\title{
Konsep Teritorialitas pada Kafe Superbee Cats
}

\author{
*Ervina Dinda Bestari ${ }^{1}$, Finta Lissimia \\ ${ }^{1,2}$ Arsitektur, Fakultas Teknik, Universitas Muhammadiyah Jakarta, Indonesia \\ 2016460016@ftumj.ac.id
}

*Alamat korespondensi, Masuk: 31 Agust. 2020, Direvisi: 08 Sept. 2020, Diterima: 19 Sept. 2020

\begin{abstract}
ABSTRAK: Komunitas pecinta hewan sangat berkembang pesat, perkembangan komunitas tersebut memunculkan kebutuhan akan fasilitas yang memadai. Komunitas berharap agar tersedia rumah hewan yang layak dan memadai bagi hewan, dimana para hewan benar - benar dirawat dan diperlakukan selayaknya makhluk hidup bukan sekedar hewan. Adanya pusat fasilitas pencinta hewan ini juga sebagai tempat perlindungan kucing-kucing liar dan bisa menjadi tempat tinggal yang nyaman dan aman untuk kucing - kucing liar. Superbee Cats adalah Tempat wisata kuliner dengan nuansa yang memadukan antara tempat wisata kuliner dengan pet care, ditempat ini para pecinta hewan khususnya pecinta kucing, disini para konsumen dapat menikmati makan dengan ditemani kucing - kucing lucu dan yang pasti sehat serta jinak. Dengan menggunakan metode deskriptif kualitatif, yaitu berusaha mendeskripsikan seluruh gejala atau keadaan yang ada. Penelitian ini memfokuskan terhadap aplikasi arsitektur teritorialitas terhadap bangunan superbee cats. Hal ini yang menjadi dasar analisis dengan mengacu kepada kebutuhan ruang berdasarkan klasifikasinya. Kesimpulan yang didapatkan dari penelitian ini adalah penerapan konsep teritorialitas pada Superbee Cats itu menggunakan tolak ukur dari tiga jenis territori umum seperti turns, use space dan stalls.
\end{abstract}

Kata kunci: Arsitektur teritorialitas, komunitas, pusat fasilitas pencinta hewan, rumah penampungan.

\begin{abstract}
Animal lovers community is growing rapidly, the development of this community raises the need for adequate facilities. The community hopes that there will be adequate and adequate animal homes for animals, where the animals are really cared for and treated like living things, not just animals. The existence of this animal lover facility is also a sanctuary for stray cats and can be a comfortable and safe place to live for wild cats. Superbee Cats is a culinary tourism spot with a nuance that combines culinary tourism with pet care, in this place for animal lovers, especially cat lovers, here consumers can enjoy eating accompanied by cute cats and certainly healthy and tame. By using a qualitative descriptive method, which tries to describe all the symptoms or conditions that exist. This study focuses on the application of territorial architecture to the superbee cats building. This is the basis of analysis with reference to space requirements based on their classification. The conclusion from this research is that the application of the concept of territoriality in the Superbee Cats uses a benchmark from three types of general territories such as turns, use space and stalls.
\end{abstract}

Keywords: Territorial architecture, animal lover facility center, community, shelter house.

\section{PENDAHULUAN}

Ibukota seperti Jakarta, komunitas pecinta hewan sangat berkembang pesat. Perkembangan komunitas tersebut memunculkan kebutuhan akan fasilitas yang memadai. Komunitas berharap agar tersedia rumah hewan yang layak dan memadai bagi hewan, dimana para hewan benar - benar dirawat dan diperlakukan selayaknya makhluk hidup bukan sekedar hewan Sudah banyak kota-kota di dunia seperti di kota Allepo yang menyediakan rumah penampungan bagi hewan-hewan terlantar [1], Korea Selatan memiliki Korean Animal Rights Advocates (KARA) [2], sebagai tempat penampungan anjing dan kucing yang terlantar. Jakarta sebagai Ibukota selayaknya mampu mengkonsepkan kebutuhan tersebut.

Adanya pusat fasilitas pencinta hewan ini bukan hanya sebagai fasilitas berkumpul untuk pecinta hewan, namun juga sebagai tempat perlindungan kucing-kucing liar dan bisa menjadi tempat tinggal yang nyaman dan aman untuk kucing-kucing liar. Anggota komunitas yang sudah mempunya kucing peliharaan sendiri juga dapat untuk berkumpul, merawat hewan peliharaan, 
membeli pernak pernik atau sekedar mengajak jalan-jalan di area walking cat area.

\section{STUDI PUSTAKA}

\section{Teritorialitas}

Teori tentang teritorialitas banyak dikemukakan oleh para ahli seperti Porteous, Pastalan, Lotman, Raffestin, Hall, Lauren, dan lain sebagainya.

Menurut KBBI, [3] istilah territory atau "wilayah" diartikan sebagai daerah (kekuasaan, pemerintahan, pengawasan); lingkungan daerah (provinsi, kabupaten, kecamatan). Sedangkan istilah territoriality atau "teritorial" diartikan sebagai bagian wilayah (daerah hukum) suatu negara. Pembentukan kawasan teritorial adalah mekanisme perilaku lain untuk mencapai privasi tertentu. Kalau mekanisme ruang personal tidak memperlihatkan dengan jelas kawasan yang menjadi pembatas antar dirinya dengan orang lain, maka pada teritorial batas batas tersebut nyata dengan tempat yang relatif tetap.

Porteous [4] berpendapat, teritorialitas sebagai batas makhluk hidup yang menentukan kepemilikan terhadap teritorial yang didalamnya terdapat suatu kontrol oleh individu ataupun kelompok untuk mempertahankan dari kemungkinan intervensi atau agresi pihak lain.

Laurens [5] berpendapat bahwa teritorialitas sebagai suatu pola tingkah laku yang merupakan perwujudan egoisme seseorang dikarenakan orang tidak ingin diganggu, atau sebagai perwujudan privasi seseorang. Indikator teritorialitas seperti papan nama, pagar batas, atau papan nama yang mencantumkan kepemilikan atau hak suatu lahan. Teritorial menurut Lang [6] merupakan ruang terbatas yang digunakan oleh individu atau kelompok yang dipertahankan sebagai tempat eksklusif. Hal ini berhubungan dengan identifikasi psikologis dengan tempat yang ditandai oleh sikap memiliki dan mengatur objek pada area tersebut.

Raffestin [7] menjelaskan bahwa teritorialitas merupakan penataan kembali ruang-ruang dan isinya, yang urutannya dapat ditemukan dalam sistem informasi berdasarkan kultur. Teritori dianggap sebagai ruang informasi dengan sistem penandaan.

Altman [8] mengklasifikasikan teritori menjadi tiga, yaitu:

1) Teritori primer (primary territory).

2) Teritori sekunder ( secondary territori).

3) Teritori umum (public territori).
Disamping itu Edney [9] mengklasifikasikan teritori umum ke dalam tiga jenis.

Stalls merupakan suatu tempat yang dapat disewa atau dipergunakan dalam jangka waktu tertentu, biasanya berkisar antara jangka waktu lama dan agak lama. Contohnya adalah kamar-kamar kos, kamar di asrama, ruangan kerja, sampai ke bilik.

Turns mirip dengan stalls, hanya berbeda dalam jangka waktu penggunaan saja. Turns di pakai orang dalam waktu yang singkat, misalnya tempat antrian karcis, antrian bensin, dan sebagainya.

Use space merupakan teritorial yang berupa ruangan yang di mulai dari titik kedudukan seseorang ke titik kedudukan objek yang sedang diamati seseorang. Contohnya adalah seseorang yang sedang mengamati lukisan dalam suatu pameran, maka ruang antara objek lukisan dengan orang yang sedang mengamati lukisan lukisan tersebut adalah "use space" atau ruangan terpakai yang dimiliki oleh orangan itu, serta tidak dapat diganggu gugat selama orang tersebut masih mengamati lukisan tersebut.

\section{METODE PENELITIAN}

Penelitian ini dilaksanakan dengan menggunakan metode deskriptif kualitatif, yaitu berusaha mendeskripsikan seluruh gejala atau keadaan yang ada.

Data yang diperoleh merupakan data primer dimana pengumpulan data melalui observasi lapangan dan wawancara dengan pihak pemilik kafe.

Analisis ini dilakukan untuk mengetahui lebih dalam mengenai obyek yang diteliti berdasarkan permasalahan dan tujuan penelitian, serta berusaha untuk mengambil kesimpulan dari penelitian yang dilakukan. Objek bangunan yang akan dibahas dalam penelitian ini yaitu kafe Superbee Cats.

\section{HASIL DAN PEMBAHASAN}

\section{Super Bee Cat}

Tempat wisata kuliner dengan nuansa yang memadukan antara tempat wisata kuliner dengan pet care. Di tempat ini para pecinta hewan khususnya pecinta kucing, disini para konsumen 
dapat menikmati makan dengan ditemani kucing kucing lucu dan yang pasti sehat serta jinak.

Terletak di jalan boulevard selatan summarecon bekasi, tempat ini tidak hanya menjadi tempat wisata kuliner saja, namun tempat ini menyediakan juga jasa penitipan kucing.

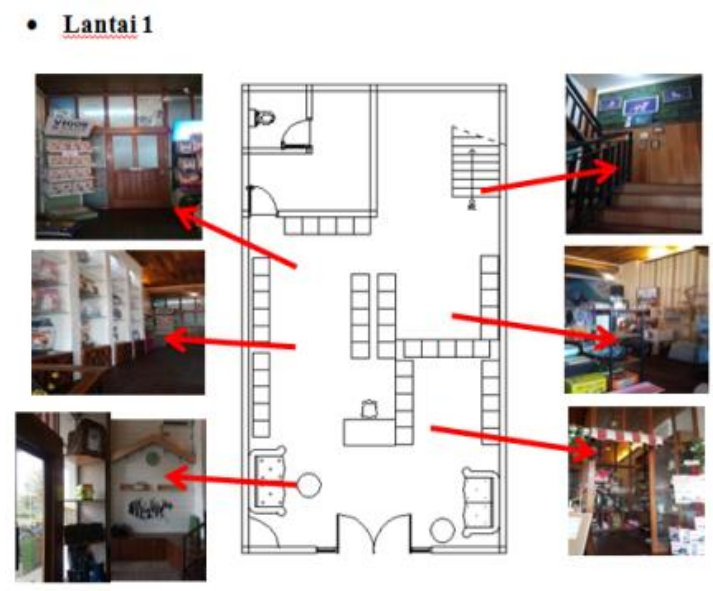

Gambar 1. Denah lantai 1 superbee cats Sumber: Dokumentasi Pribadi

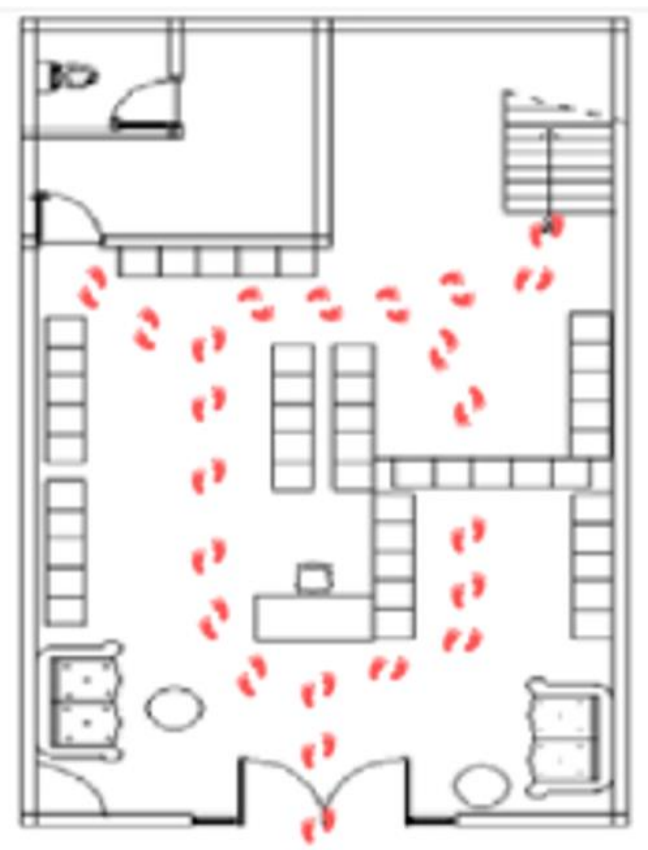

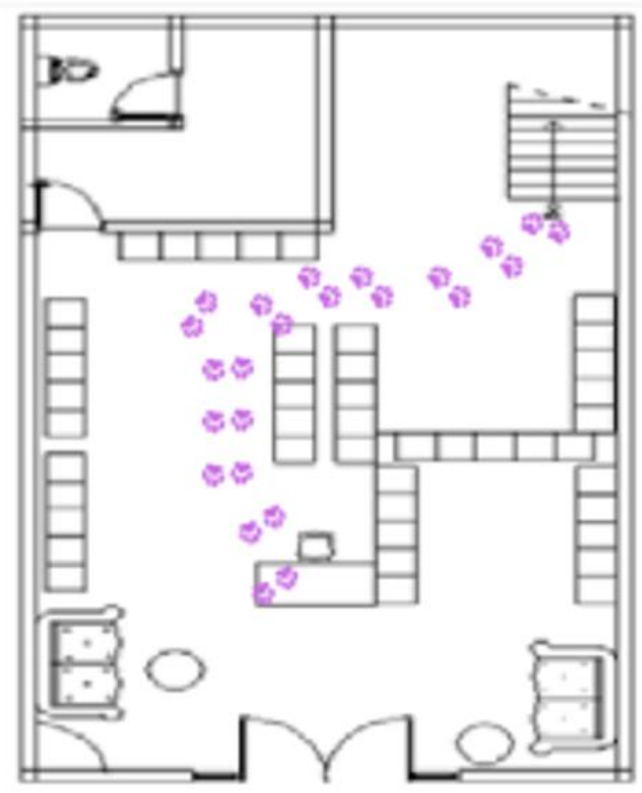

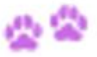

Gambar 2. Alur gerak manusia

Sumber: Dokumentasi Pribadi

Ruangan ini di lalui oleh manusia dalam jangka waktu singkat seperti memilih, membeli, dan membayar, gerakan manusia di ruangan ini lebih leluasa karena lebih di khususkan untuk manusia.

Kucing di lantai pertama ini hanya sekedar lewat atau 1 kucing saja yang kadang menetap di bawah, karena ruangan ini bukan untuk kucing.

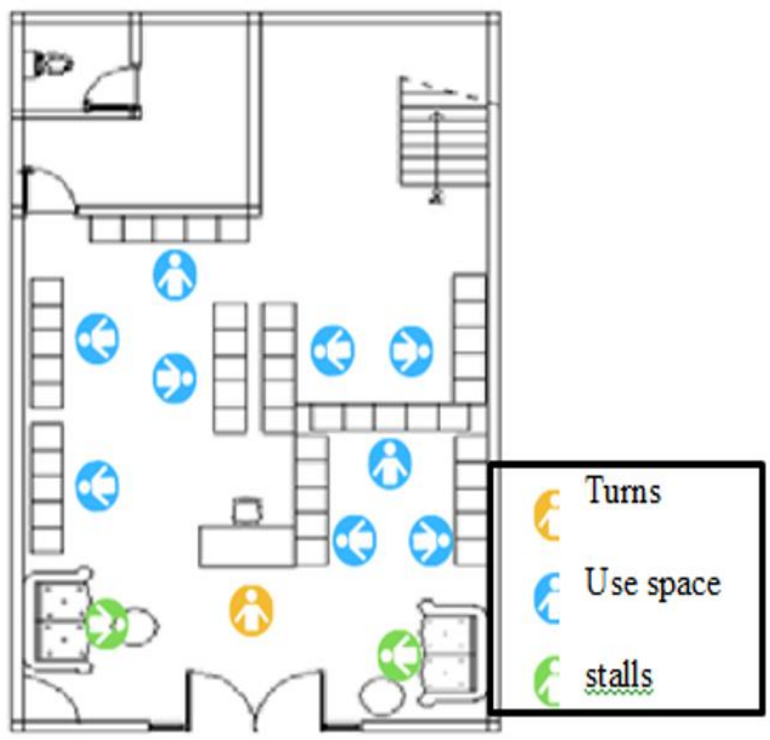

Gambar 3. Analisis penzoningan

Sumber: Dokumentasi Pribadi 
- Turns

Di lalui dengan waktu singkat, hanya untuk membayar

- Use space

Di lalui untuk memilih dan menentukan apa yang harus di beli

- Stalls

Di tempati untuk menunggu giliran ke dalam café atau menunggu saat membeli

- Lantai 2

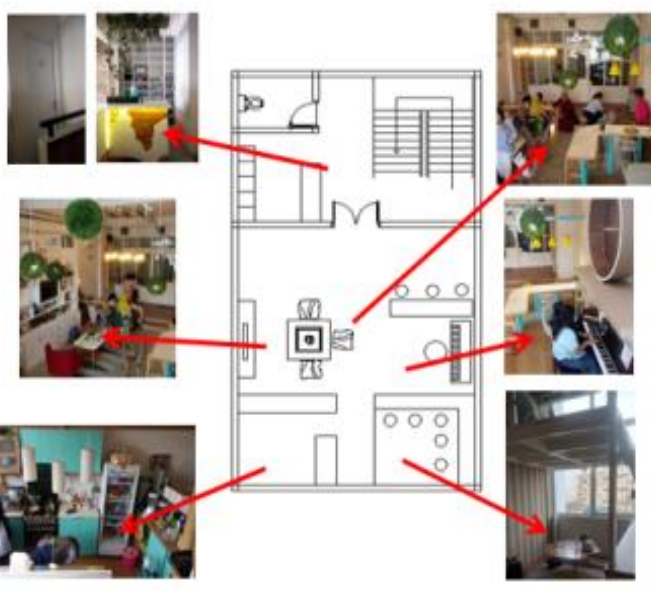

Gambar 4. Denah lantai 2 superbee cats Sumber: Dokumentasi Pribadi

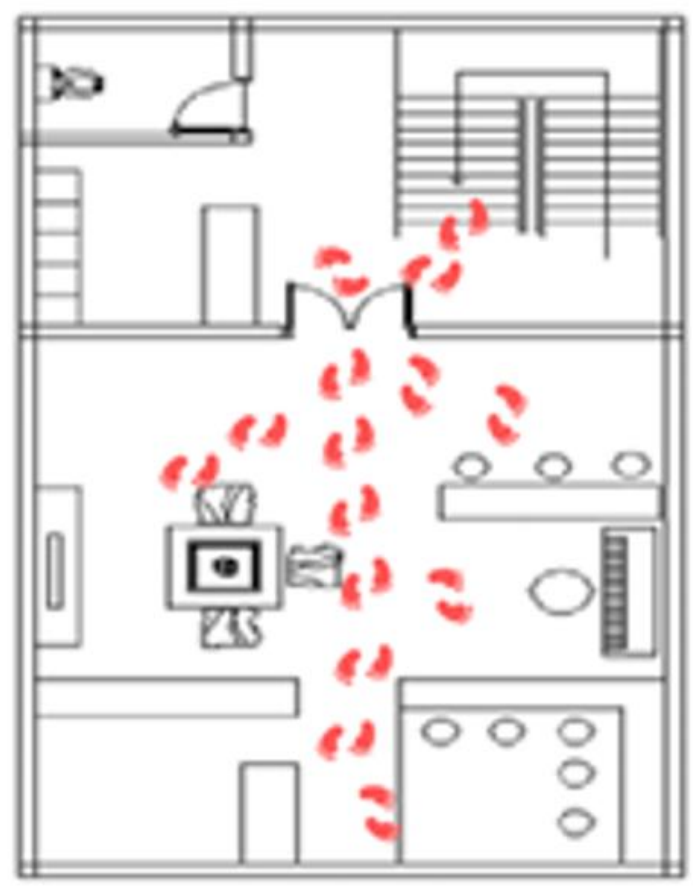

Langkah geral manusia

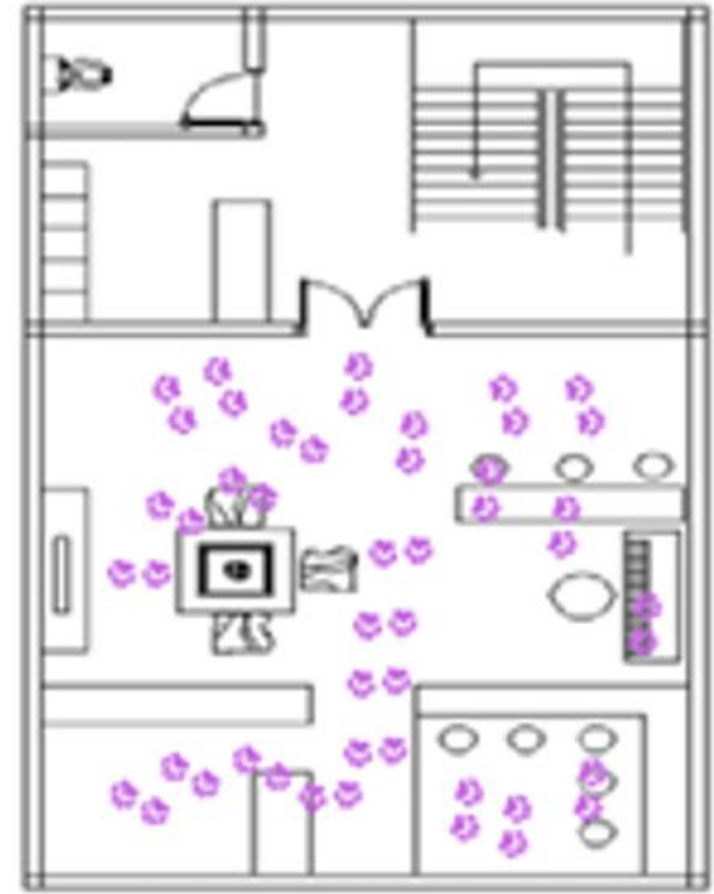

\section{Langkah gerak bucing}

Gambar 5. Alur gerak manusia Sumber: Dokumentasi Pribadi

Kegiatan kucing di ruangan ini sangat bebas, bebas untuk menelusuri ke setiap sudut ruang karena memang ruangan tersebut bertujuan untuk kucing dan manusia berbaur bersama, hanya bagian dapur hanya staff yang bisa masuk ke dalamnya

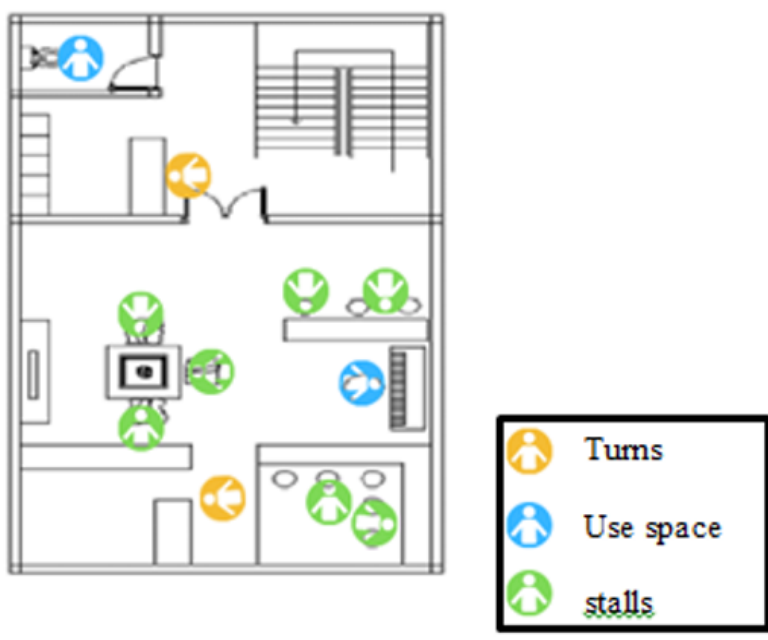

Gambar 6. Analisis penzoningan Sumber: Dokumentasi Pribadi 
- Turns

Di lalui untuk menitipkan sepatu dan mengambil sepatu yang harus di lepas ketika masuk ke dalam café, dan memesan makanan dan minuman

- Use space

Menggunakan kamar mandi hanya untuk buat air kecil yang tidak menggunakan waktu yang lama dan untuk memainkan music dengan waktu sebentar

- Stalls

Memakan dan meminum dengan jangka waktu yang agak lama dan sembari dengan bermain dengan kucing-kucing di dalam kafe lalu berbincang dengan teman maupun keluarga.

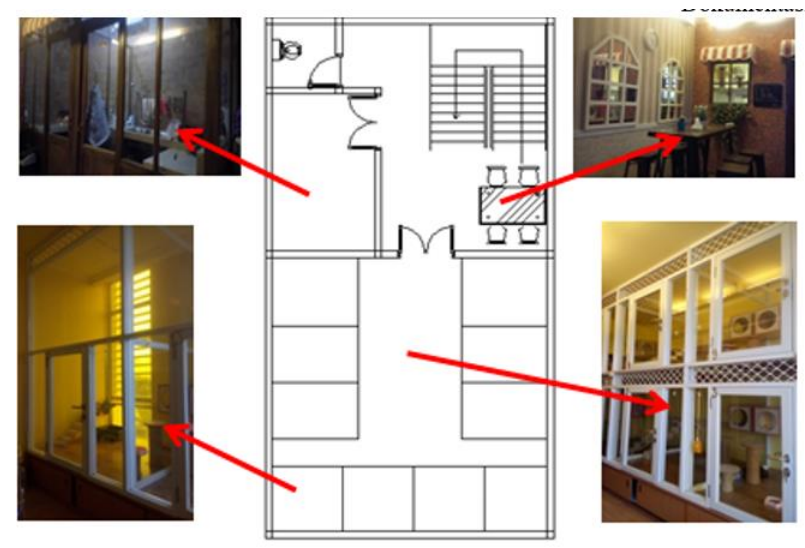

Gambar 7. Denah lantai 3 superbee cats Sumber: Dokumentasi Pribadi

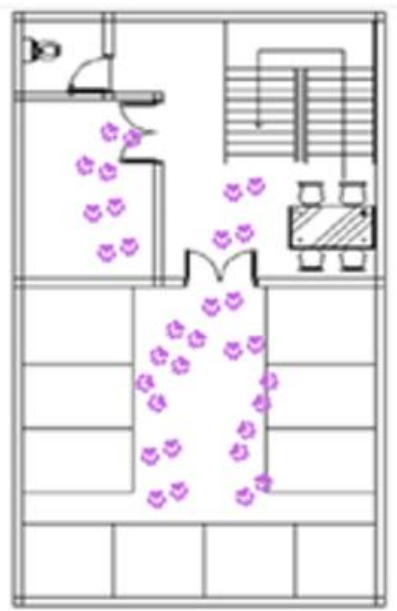

$\alpha$

L angkah gerak kucing

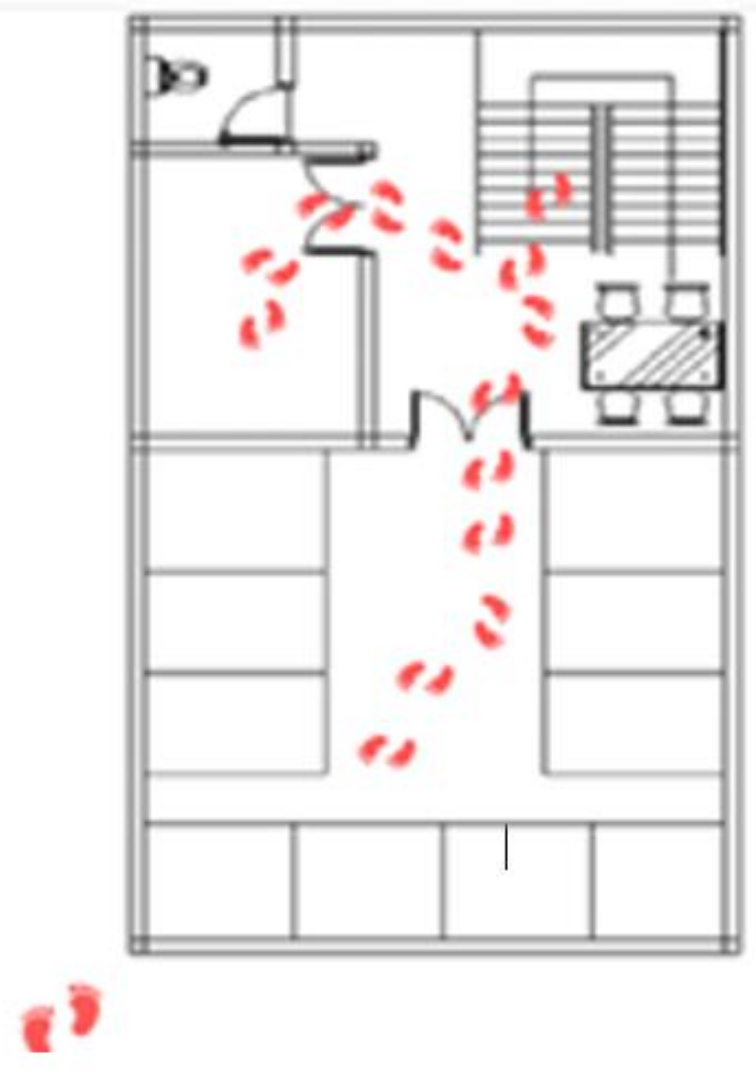

Gambar 8. Alur gerak manusia Sumber : Dokumentasi Pribadi

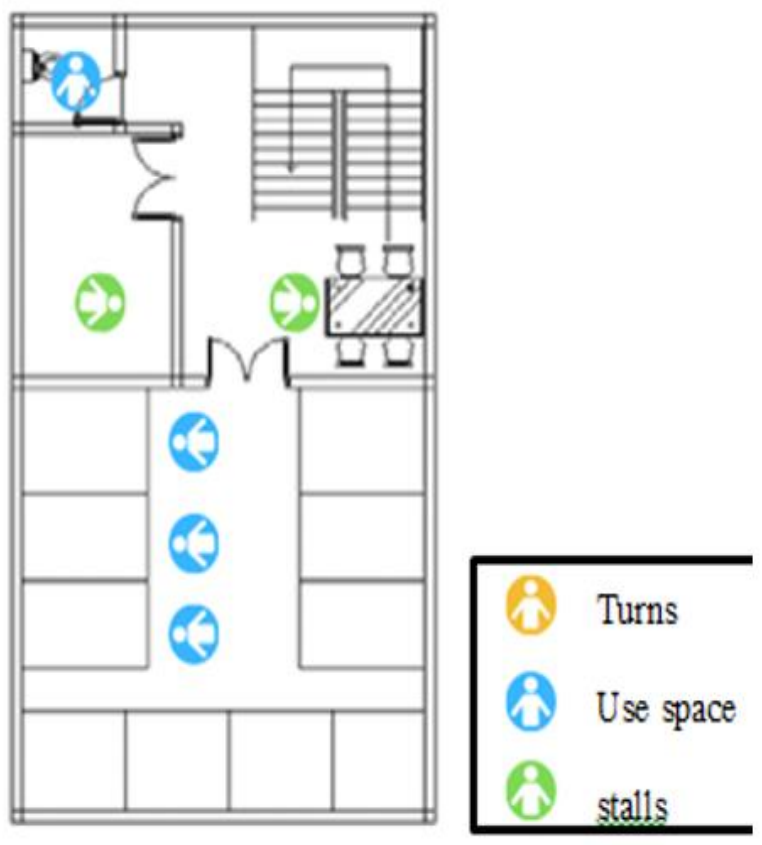

Gambar 9. Analisis penzoningan Sumber : Dokumentasi Pribadi 
- Use space

Untuk memeriksa kucing yang sedang di dalam hotel kucing, untuk memberi makan dan minum, memasuk keluarkan kucing kedalam hotel untuk antara jemput ketika pelanggan dan untuk menitipkan maupun menjemput kucing mereka

- Stalls

Melakukan kegiatan grooming dan pengunjung untuk melihat kucing peliharaannya sedang dalam proses grooming

Berdasarkan pada data dan analisis di atas, pada lantai ketiga ruang territorial yang terjadi, adanya batasan territorial pada manusia dan hewan, ketika hewan masuk kedalam hotel khusus kucing, manusia tidak dapat masuk ke dalam karena dimensi ruangan yang hanya cukup untuk si kucing, sedangkan manusia dapat menunggu di tempat ruang tunggu di depan ruangan grooming untuk menjemput ataupun mengantur kucing peliharaanya

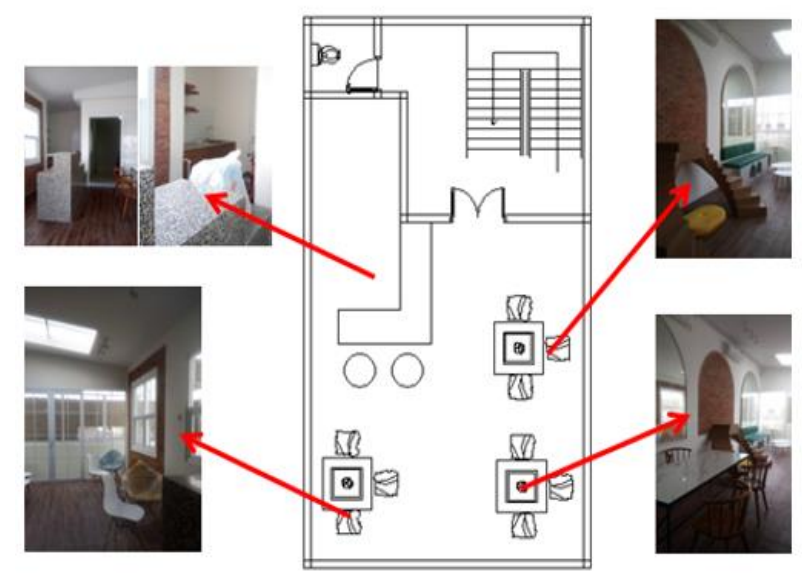

Gambar 10 : Denah lantai 4 superbee cats

Sumber : Dokumentasi Pribadi

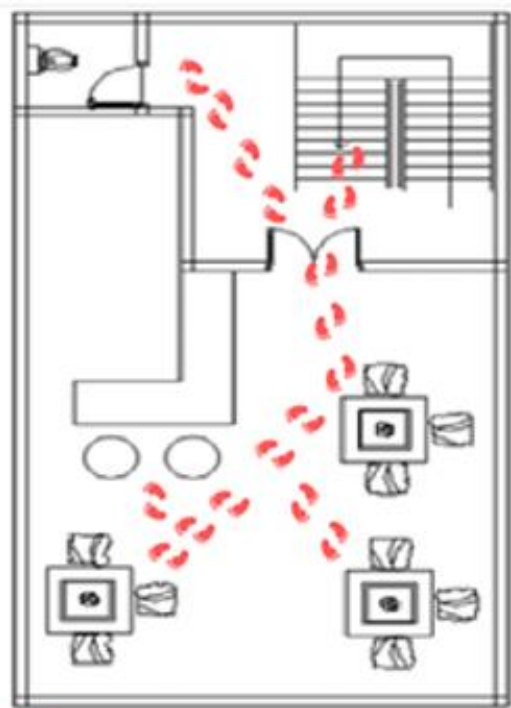

Langkah gerak manusia

Gambar 11. Alur gerak manusia Sumber : Dokumentasi Pribadi

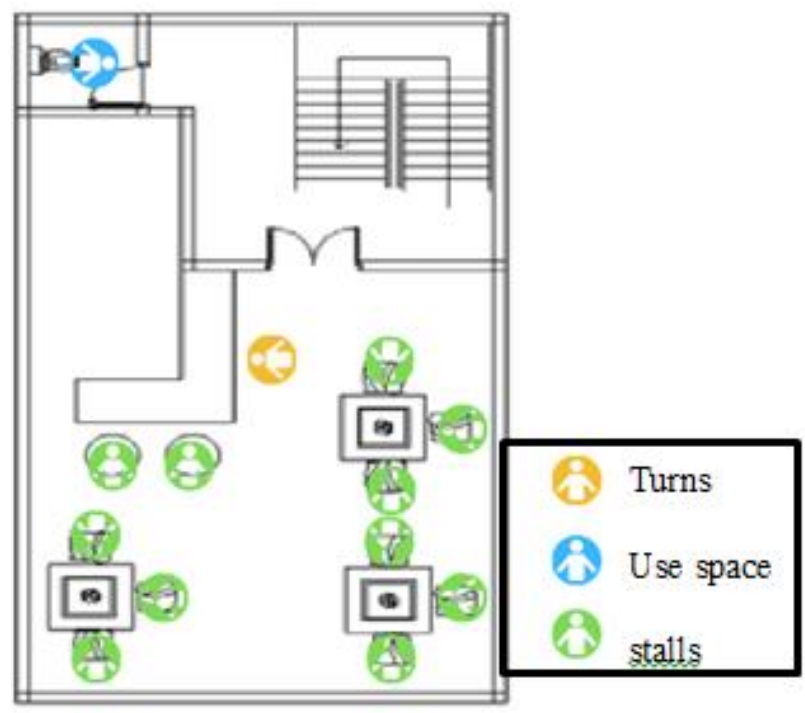

Gambar 12. analisis penzoningan Sumber: Dokumentasi Pribadi

- Turns

Di lalui untuk memesan dan membayar.

- Use space

Di lalui untuk kegiatan buang air kecil yang di lakukan dengan waktu yang singkat. 
- Stall

Melakukan kegiatan memakan dan menikmati secangkir kopi yang di pesan perseorangan maupun berkelompok.

\section{KESIMPULAN DAN SARAN}

Penerapan konsep teritorialitas pada Superbee Cats itu menggunakan tolak ukur dari tiga jenis territori umum seperti turns, use space dan stalls.

Pada turns di superbee cats itu menjelaskan tentang kegiatan yang singkat serta tidak memerlukan waktu yang cukup lama seperti, memesan dan membayar, menitipkan barang.
Pada use space di superbee cats itu menjelaskan tentang kegiatan dengan waktu sedikit lebih lama seperti menggunakan toilet dan antar jemput hewan peliharaan.

Pada stalls di superbee cats itu menjelaskan tentang kegiatan yang cukup lama seperti makan dan minum di tempat yang disediakan atau sedang berkumpul dengan teman dan keluarga di kafe bersama kucing-kucing atau berkumpul di coffee shop pada lantai 4, dan pada hewan peliharaan bisa dengan waktu lama di dalam hotel khusus kucing di lantai 3.

\section{DAFTAR PUSTAKA}

[1] Widyaningrum GL. (2019). Di Tengah Perang Suriah, Pria Pecinta Kucing Ini Dirikan Klinik Hewan. https://nationalgeographic.grid.id/read/131901602/di-tengah-perang-suriah-pria-pecinta-kucing-ini-dirikanklinik-hewan., diakses pada: 19 Agustus 2020.

[2] IAKA. (2019). Many Koreans continue to catch, breed, and slaughter these animals for profit alone. http://koreananimals.org/, diakses pada: 18 September 2020.

[3] KKBI. (2020). KKBI Daring. https://kbbi.kemdikbud.go.id/entri/wilayah, diakses pada: 19 September 2020.

[4] Porteous JD. (1977) Environment \& behavior: planning and everyday urban life.

[5] Laurens JM. (2004) Arsitektur dan perilaku manusia. Penerbit PT Grasindo.

[6] Lang J (1987) Privacy, Territoriality, and Personal Space-Proxemic Theory. Creating Architectural Theory: The role of the behavioral sciences in design, New York: Hal. 145-156.

[7] Raffestin C (2012) Space, territory, and territoriality. Environment planning D: society space Vol. 30, No. 1: Hal. 121-141.

[8] Altman I (1975) The Environment and Social Behavior: Privacy, Personal Space, Territory, and Crowding.

[9] Edney J (1976) Comment on Functional Properties. Environment behavior Vol. 8, No. 1: Hal. 31-47.

(C) 2020 the Author(s), licensee Jurnal LINEARS. This is an open-access article distributed under the terms of the Creative Commons Attribution License

(http://creativecommons.org/licenses/by/4.0) 